\title{
Early sedation and clinical outcomes of mechanically ventilated patients: a prospective multicenter cohort study
}

Lilian Maria Sobreira Tanaka', Luciano Cesar Pontes Azevedo ${ }^{2,3}$, Marcelo Park ${ }^{2,3}$, Guilherme Schettino², Antonio Paulo Nassar Jr ${ }^{4}$, Alvaro Réa-Neto ${ }^{5}$, Luana Tannous ${ }^{5}$, Vicente Ces de Souza-Dantas ${ }^{6,7}$, André Torelly ${ }^{8}$, Thiago Lisboa ${ }^{8}$, Claudio Piras ${ }^{9}$, Frederico Bruzzi Carvalho ${ }^{10}$, Marcelo de Oliveira Maia ${ }^{11}$, Fabio Poianas Giannini ${ }^{12}$, Flavia Ribeiro Machado ${ }^{13}$, Felipe Dal-Pizzol ${ }^{14}$, Alexandre Guilherme Ribeiro de Carvalho ${ }^{15}$, Ronaldo Batista dos Santos ${ }^{16}$, Paulo Fernando Guimarães Morando Marzocchi Tierno ${ }^{17}$, Marcio Soares ${ }^{18,19}$, Jorge Ibrain Figueira Salluh ${ }^{18,19^{*}}$ and for the ERICC study investigators

\begin{abstract}
Introduction: Sedation overuse is frequent and possibly associated with poor outcomes in the intensive care unit (ICU) patients. However, the association of early oversedation with clinical outcomes has not been thoroughly evaluated. The aim of this study was to assess the association of early sedation strategies with outcomes of critically ill adult patients under mechanical ventilation (MV).
\end{abstract}

Methods: A secondary analysis of a multicenter prospective cohort conducted in 45 Brazilian ICUs, including adult patients requiring ventilatory support and sedation in the first 48 hours of ICU admissions, was performed. Sedation depth was evaluated after 48 hours of MV. Multivariate analysis was used to identify variables associated with hospital mortality.

Results: A total of 322 patients were evaluated. Overall, ICU and hospital mortality rates were $30.4 \%$ and $38.8 \%$, respectively. Deep sedation was observed in 113 patients (35.1\%). Longer duration of ventilatory support was observed (7 (4 to 10) versus 5 ( 3 to 9$)$ days, $P=0.041)$ and more tracheostomies were performed in the deep sedation group (38.9\% versus $22 \%, P=0.001$ ) despite similar $\mathrm{PaO}_{2} / \mathrm{FiO}_{2}$ ratios and acute respiratory distress syndrome (ARDS) severity. In a multivariate analysis, age (Odds Ratio (OR) 1.02; 95\% confidence interval (CI) 1.00 to 1.03), Charlson Comorbidity Index >2 (OR 2.06; 95\% Cl, 1.44 to 2.94), Simplified Acute Physiology Score 3 (SAPS 3) score (OR 1.02; Cl 95\%, 1.00 to 1.04), severe ARDS (OR 1.44; Cl 95\%, 1.09 to 1.91) and deep sedation (OR 2.36; Cl $95 \%, 1.31$ to 4.25 ) were independently associated with increased hospital mortality.

Conclusions: Early deep sedation is associated with adverse outcomes and constitutes an independent predictor of hospital mortality in mechanically ventilated patients.

\footnotetext{
* Correspondence: jorgesalluh@gmail.com

${ }^{18}$ IDOR - D'Or Institute for Research and Education, Rua Diniz Cordeiro 30,

Rio de Janeiro 22281-100, Brazil

${ }^{19}$ Postgraduate Program, Instituto Nacional de Câncer, $10^{\circ}$ Andar, Praça Cruz

Vermelha 23, Rio de Janeiro 20230-130, Brazil

Full list of author information is available at the end of the article
}

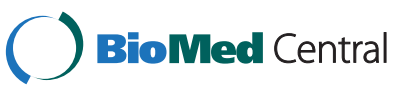

(c) 2014 Tanaka et al.; licensee BioMed Central Ltd. This is an Open Access article distributed under the terms of the Creative Commons Attribution License (http://creativecommons.org/licenses/by/4.0), which permits unrestricted use, distribution, and reproduction in any medium, provided the original work is properly credited. The Creative Commons Public Domain Dedication waiver (http://creativecommons.org/publicdomain/zero/1.0/) applies to the data made available in this article, unless otherwise stated. 


\section{Introduction}

Sedation is an important component of care for patients under mechanical ventilation (MV) in the ICU. Significant distress is related to MV itself or to routine procedural interventions [1] and minimizing pain, anxiety and distress is a major recommendation in recent guidelines [2]. Pain and anxiety control is usually obtained with analgesics and sedatives that ensure comfort, improve synchrony with the ventilator and decrease work of breathing [3]. Some studies, however, have shown that oversedation is associated with poor outcomes, including delirium, prolonged $\mathrm{MV}$, ventilator-associated pneumonia, long ICU and hospital length of stay [3-6], posttraumatic stress disorder [7] and cognitive impairment $[8,9]$ as well as increased costs [10-12]. Nevertheless, the issue of early sedation has seldom been evaluated, especially in randomized controlled studies.

Despite the current recommendations [2], there is still a significant gap between evidence from recent trials and implementation in clinical practice $[2,6,13,14]$. Moreover, to date no large randomized controlled trials of sedation strategies used mortality as the primary outcome. In addition, clinical trials of sedation have until now enrolled patients mostly after 24 to 48 hours following initiation of MV, resulting in inadequate assessment of early sedation practice and its association with clinically relevant outcomes [15-17].

The aim of this study is thus to describe the association of early sedation strategies (sedation depth and sedative choice) with clinical outcomes of mechanically ventilated adult ICU patients, with hospital mortality as the primary outcome.

\section{Materials and methods}

\section{Study design, patient selection and definitions}

This study was a secondary analysis of a multicenter prospective cohort conducted in 45 Brazilian ICUs (from the Brazilian Research in Intensive Care Network) from 12 states between 1 June 2011 and 31 July 2011 [18]. Additional file 1 presents the participating ICUs in more detail. In the present study, adult patients ( $\geq 18$ years old) requiring invasive ventilatory support in the first 48 hours of ICU admission using sedatives on the second day of MV were included.

We excluded patients submitted exclusively to noninvasive MV and those presenting with primary neurological disorders. We also excluded those with missing data regarding sedation depth on the second day of MV. Demographic, clinical and laboratory data were collected during the ICU stay and included cause of respiratory failure, chronic health status, Charlson Comorbidity Index [19], Simplified Acute Physiology Score 3 (SAPS3) [20] and the Sequential Organ Failure Assessment (SOFA) score [21]. Data regarding the need for vasopressors, tracheostomy and renal replacement therapy were also reported. Sepsis diagnosis was made based on current definitions [22]. A patient was considered to have an infection when presenting with suggestive clinical, laboratory, radiographic and microbiological findings that justified the administration of antibiotics (excluding prophylaxis) [23]. Acute respiratory distress syndrome (ARDS) was defined and classified according to the Berlin definition [24].

As the primary study was not designed to evaluate sedation strategies [18], the Glasgow Coma Scale (GCS) originally reported for SOFA score calculation - was used as a surrogate for sedation depth. Light sedation was defined as GCS $\geq 9$ whereas those patients with GCS $<9$ were considered deeply sedated. Reliability of GCS as a surrogate for the Richmond Agitation-Sedation Scale (RASS) as well as selection of GCS $=9$ as the cutoff value were based on the study by Ely and colleagues that demonstrated an excellent correlation $(r=0.91, P<0.001)$ between the GCS and RASS, where GCS $=9$ would be equivalent to RASS $=-2$ [25].

Our primary hypothesis was that early sedation strategies, namely sedation depth, could be associated with clinical outcomes including hospital mortality, so we chose to evaluate the sedation level on the second day of MV.

The study was approved by the institutional review board of Hospital Sírio-Libanês at the coordinating center (Comitê de Ética em Pesquisa; approval number HSL 2010/ 51) and subsequently by local review boards. Additional file 1 describes the local review boards by participating hospital. Due to the observational nature of the study, the following institutions waived the need for informed consent: Comitê de Ética em Pesquisa - Hospital São Camilo; Comitê de Ética em Pesquisa - Hospital Sírio-Libanês; Comissão de Ética para Análise de Projetos de Pesquisa HCFMUSP; Comitê de Ética em Pesquisa - Hospital das Clinicas de Niteroi; Comitê de Ética em Pesquisa - Hcor; Comitê de Ética em Pesquisa - Hospital Israelita Albert Einstein; Comitê de Ética em Pesquisa - HCFMRP USP; Comitê de ética do Hospital Sao Jose; Comitê de Ética em Pesquisa do Vitória Apart Hospital; Comitê de Ética em Pesquisa do Hospital Madre Teresa; Comitê de Ética em Pesquisa do Hospital da Mulher Heloneida Studart; Comitê de Ética em Pesquisa - Hospital Moinhos de Vento; Comitê de Ética em Pesquisa do Hospital Mater Dei; Comitê de Ética em pesquisa - Hospital Mario Lioni; Comitê de Ética e Pesquisa do Hospital Espanhol; Comitê de Ética em Pesquisa - Instituto de Pesquisa Clínica Evandro Chagas, Fundação Oswaldo Cruz; Comitê de Ética em Pesquisa - UNIFESP/EPM; Comitê de Ética em Pesquisa - Hospital Copa D'or; Comitê de Ética em Pesquisa - Beneficiência Médica Brasileira S/A Hospital São Luiz; Comitê de Ética em Pesquisa do Hospital do Trabalhador; Comitê de Ética em Pesquisa da Fundação de Medicina Tropical do Tocantins; and Comitê de Ética em Pesquisa - FMUSP. 


\section{Statistical analysis}

Continuous variables are reported as the median (25 to $75 \%$ interquartile range). Univariate and multivariate analyses using a binary logistic regression were used to identify factors associated with the dependent variable (hospital mortality). Variables yielding $P<0.2$ by univariate analysis, or those considered clinically relevant despite $P$ values, were entered into the multivariate analysis to estimate the independent association of each covariate with the dependent variable. Results are presented as the odds ratio with 95\% confidence interval. A Kaplan-Meier curve with log-rank test was used to compare patients with light versus deep sedation for hospital mortality (censored at day 30 ). Two-tailed $P<0.05$ was considered statistically significant. All statistical tests were carried out using the commercial SPSS19.0 package for Windows (SPSS Inc., Chicago, IL, USA).

\section{Results}

\section{Characteristics of the study population}

From 773 patients derived from the original cohort, a total of 322 patients fulfilled the eligibility criteria (Figure 1). Patients excluded for missing data about sedation depth on day $2(n=51)$ were comparable with the included population regarding demographic data, comorbidities, physiologic and disease severity variables and outcomes (data not shown). The main patient characteristics are presented in Table 1. Median ( 25 to $75 \%$ interquartile range) age was 59 (41 to 74 ) years. The median SAPS3 was 61 (50 to 72 ) and SOFA score was 8 (6 to 11 ) on the first day in the ICU. Overall ICU and hospital mortality rates were $30.4 \%$ and $38.8 \%$ respectively. When comparing nonsurvivor and survivor subgroups, we observed that nonsurvivors showed higher median age (68 (52 to 77) years vs. 53 (34 to 69) years, $P<0.001$ ), higher SAPS3 and SOFA score (68 (57 to 79 ) vs. 57 (48 to 67 ), $P<0.001$ and 10 (7 to 12 ) vs. 8 (5 to 10$), P<0.001$ ) and higher percentage of patients with a Charlson Comorbidity Index $>2(37.6 \%$ vs. $16.2 \%$, $P<0.001)$. Those who died during hospital admission also had a higher frequency of moderate/severe ARDS (24\% vs. 9.6\%, $P=0.004)$, need for vasopressors $(85.6 \%$ vs.71.1\%, $P=$ $0.003)$ and renal replacement therapy (33.6\% vs.13.7\%, $P<0.001)$.

\section{Sedative choice and sedation depth}

The most frequently used sedatives were the association of midazolam and fentanyl (39.4\%) or of propofol and fentanyl (14\%) and the use of fentanyl (12.4\%) or midazolam $(8.1 \%)$ as single drugs. Sedative drug type was also associated with sedation levels: the sole administration of fentanyl and dexmedetomidine was more frequent in lightly sedated patients $(15.3 \%$ vs. $7.1 \%$ for fentanyl, $P=0.033$; $8.6 \%$ vs. $0.9 \%$ for dexmedetomidine, $P=0.005$ ).

Deep sedation was observed in 113 patients (35.1\%) and was associated with a higher overall disease severity, as demonstrated by higher median SAPS 3 (65 (54 to 78) for deep sedation vs. 59 (48 to 70 ) for light sedation, $P=$ 0.001) (Table 2). Moreover, longer duration of ventilatory support was observed ( 7 ( 4 to 10$)$ vs. 5 (3 to 9 ) days, $P=$ 0.041 ) and more tracheostomies were performed in the deep sedation group ( $38.9 \%$ vs. $22 \%, P=0.001)$ despite similar arterial partial pressure of oxygen/fraction of inspired oxygen ratios and ARDS severity. Finally, trends to increased ICU and hospital mortality (37.2\% vs. $26.8 \%, P=$ 0.054 and $46 \%$ vs. $34.9 \%, P=0.051$ respectively) were also associated with deep sedation (Table 3). A survival curve comparing patients with deep and light sedation is shown in Figure 2.

In a multivariate analysis, age, Charlson Comorbidity Index $>2$, SAPS3, severe ARDS and deep sedation were independently associated with increased hospital mortality (Table 4).

\section{Discussion}

In the present multicenter cohort study we evaluated the association of early sedation strategies with outcomes of adult mechanically ventilated patients in the ICU. Deep sedation in the first 48 hours of MV is a common

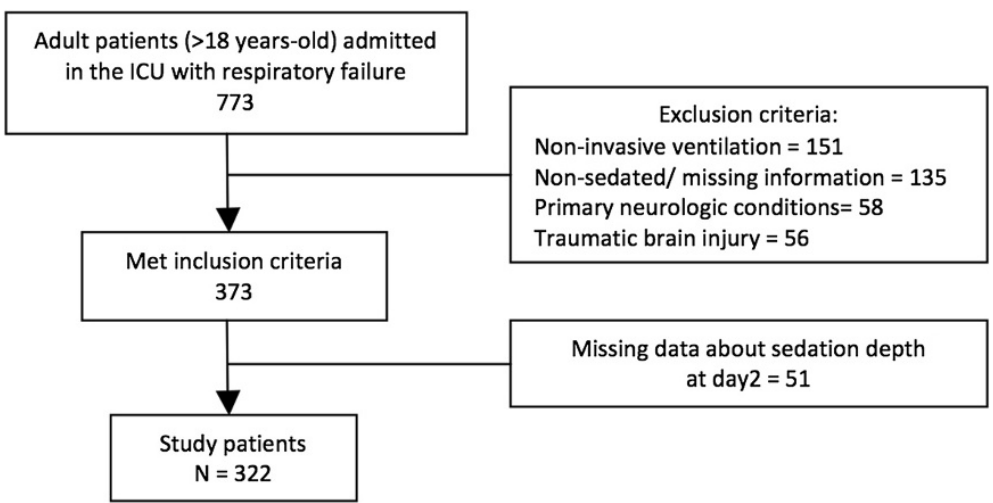

Figure 1 Study flow diagram. 
Table 1 General characteristics of study patients according to survival status

\begin{tabular}{|c|c|c|c|}
\hline Characteristic & Survivors $(n=197)$ & Nonsurvivors $(n=125)$ & $P$ value $^{\mathrm{a}}$ \\
\hline Age (years) & 53 (34 to 69) & 68 (52 to 77) & $<0.001$ \\
\hline Male gender & $114(58)$ & $73(58)$ & 0.925 \\
\hline Admission SAPS3 (points) & 57 (48 to 67) & 68 (57 to 79$)$ & $<0.001$ \\
\hline SOFA score day 1 (points) & $8(5$ to 10$)$ & $10(7$ to 12$)$ & $<0.001$ \\
\hline \multicolumn{4}{|l|}{ Charlson comorbidity index } \\
\hline 0 & $106(53.8)$ & $30(24)$ & \\
\hline 1 to 2 & $59(29.9)$ & $48(38.4)$ & $<0.001$ \\
\hline$>2$ & $32(16.2)$ & 47 (37.6) & \\
\hline Admission source & & & 0.038 \\
\hline Ward & $52(26.4)$ & $49(39.2)$ & \\
\hline Emergency room & $79(40.1)$ & $46(36.8)$ & \\
\hline Operation room & $66(33.5)$ & $30(24)$ & \\
\hline \multicolumn{4}{|l|}{ Cause of respiratory failure } \\
\hline Pneumonia & $66(33.5)$ & $39(31.2)$ & 0.668 \\
\hline Nonpulmonary sepsis & $30(15.2)$ & $15(12)$ & 0.415 \\
\hline Asthma/COPD & $23(11.7)$ & $7(5.6)$ & 0.068 \\
\hline Cardiogenic pulmonary edema & $11(5.6)$ & $9(7.2)$ & 0.558 \\
\hline Extracranial trauma & $11(5.6)$ & $12(9.6)$ & 0.173 \\
\hline Hypovolemic/cardiogenic shock & $10(5.1)$ & $8(6.4)$ & 0.614 \\
\hline Aspirative syndromes & $10(5.1)$ & $3(2.4)$ & 0.234 \\
\hline Pulmonary embolism & $4(2)$ & $5(4)$ & 0.296 \\
\hline Others & $32(16.2)$ & 27 (21.6) & 0.226 \\
\hline \multicolumn{4}{|l|}{ Comorbidities } \\
\hline Hypertension & $63(32)$ & $58(46.4)$ & 0.008 \\
\hline Diabetes & $30(15.2)$ & $42(33.6)$ & $<0.001$ \\
\hline Heart failure & $12(6.1)$ & $14(11.2)$ & 0.101 \\
\hline COPD & $12(6.1)$ & $12(9.6)$ & 0.243 \\
\hline Chronic renal failure & $11(5.6)$ & $23(18.4)$ & $<0.001$ \\
\hline \multicolumn{4}{|l|}{ Respiratory data } \\
\hline ARDS mild & $29(14.7)$ & $21(16.8)$ & 0.004 \\
\hline ARDS moderate/severe & $19(9.6)$ & $30(24)$ & \\
\hline $\mathrm{PO}_{2} / \mathrm{FiO}_{2}$ ratio & 287 (220 to 350$)$ & 252 (184 to 328$)$ & 0.019 \\
\hline Tracheostomy & $54(27.4)$ & $36(28.8)$ & 0.817 \\
\hline Extubation failure & $23(11.7)$ & $19(15.2)$ & 0.182 \\
\hline Length of ventilatory support (days) & 5 (3 to 8 ) & $6(3$ to 11$)$ & 0.260 \\
\hline \multicolumn{4}{|l|}{ ICU support } \\
\hline Renal replacement therapy & $27(13.7)$ & $42(33.6)$ & $<0.001$ \\
\hline Vasopressors & $140(71.1)$ & $107(85.6)$ & 0.003 \\
\hline \multicolumn{4}{|l|}{ Outcomes } \\
\hline ICU length of stay (days) & 11 (7 to 19$)$ & $11(5$ to 18.5$)$ & 0.389 \\
\hline Hospital length of stay (days) & 23 (14 to 36$)$ & 14.5 (7.3 to 27$)$ & $<0.001$ \\
\hline
\end{tabular}




\section{Table 1 General characteristics of study patients according to survival status (Continued)}

Sedation depth

$\begin{array}{lll}\text { Light sedation } & 136(69.0) & 73(58.4) \\ \text { Deep sedation } & 61(31.0) & 52(41.6)\end{array}$

Data presented as median ( 25 to $75 \%$ interquartile range) or $n$ (\%). ARDS, acute respiratory distress syndrome; COPD, chronic obstructive pulmonary disease; $\mathrm{PO}_{2} / \mathrm{FiO}_{2}$, arterial partial pressure of oxygen/fraction of inspired oxygen; SAPS3, Simplified Acute Physiology Score 3; SOFA, Sequential Organ Failure Assessment. ${ }^{a} P$ value of the comparison between survivors and nonsurvivors.

characteristic, observed in $35.1 \%$ of patients. Deep sedation was associated with increased disease severity, longer duration of ventilatory support and higher need for tracheostomy. In a multivariate analysis, deep sedation was an independent factor associated with increased hospital mortality (odds ratio $=2.36$ ).
The more frequently used sedative regimens in our study were the association of midazolam and fentanyl or of propofol and fentanyl. When compared by sedation depth, the administration of fentanyl or dexmedetomidine as single drugs was more frequent in lightly sedated patients $(15.3 \%$ vs. $7.1 \%$ for fentanyl, $P=0.033 ; 8.6 \%$ vs. $0.9 \%$

Table 2 General characteristics of study patients according to sedation depth

\begin{tabular}{|c|c|c|c|c|}
\hline Characteristic & All patients $(n=322)$ & Light sedation $(n=209)$ & Deep sedation $(n=113)$ & $P$ value $^{\mathrm{a}}$ \\
\hline Age (years) & 59 (40.8 to 74$)$ & 61 (44 to 74.5$)$ & 55 (33.5 to 73) & 0.068 \\
\hline Male gender & $187(58)$ & $108(52)$ & $79(70)$ & 0.002 \\
\hline \multicolumn{5}{|l|}{ Charlson comorbidity index } \\
\hline 0 & $136(42.2)$ & $72(34.4)$ & $64(56.7)$ & \multirow[t]{3}{*}{$<0.001$} \\
\hline 1 to 2 & $107(33.2)$ & 75 (35.9) & $32(28.3)$ & \\
\hline$>2$ & $79(24.5)$ & $62(29.7)$ & $17(15)$ & \\
\hline \multicolumn{5}{|l|}{ Comorbidities } \\
\hline Hypertension & $121(37.7)$ & $88(42.1)$ & $33(29.2)$ & 0.026 \\
\hline Diabetes & $72(22.4)$ & $50(25.4)$ & $22(17.6)$ & 0.381 \\
\hline Heart failure & $26(8.1)$ & $21(10.7)$ & $5(14.7)$ & 0.077 \\
\hline COPD & $24(7.5)$ & $21(10)$ & $3(2.7)$ & 0.016 \\
\hline Chronic renal failure & $34(10.6)$ & $24(12.2)$ & $10(8)$ & 0.463 \\
\hline Admission source & & & & 0.103 \\
\hline Ward & $101(31.4)$ & $74(35.4)$ & $27(23.9)$ & \\
\hline Emergency room & $125(38.8)$ & $77(36.8)$ & $48(42.5)$ & \\
\hline Operation room & $96(29.8)$ & $58(27.8)$ & 38 (33.6) & \\
\hline \multicolumn{5}{|l|}{ Admission scores (points) } \\
\hline Admission SAPS3 & 61 (50 to 72 ) & 59 (48 to 70$)$ & 65 (54 to 78$)$ & 0.001 \\
\hline SOFA score day 1 & 8 (6 to 11$)$ & 8 (5 to 11$)$ & $9(7$ to 11$)$ & 0.001 \\
\hline \multicolumn{5}{|l|}{ Cause of respiratory failure } \\
\hline Pneumonia & 105 (32.6) & $69(33)$ & $36(31.9)$ & 0.833 \\
\hline Nonpulmonary sepsis & $45(14)$ & $30(14.4)$ & $15(13.3)$ & 0.790 \\
\hline Asthma/COPD & $30(9.3)$ & $19(9.1)$ & $11(9.7)$ & 0.850 \\
\hline Cardiogenic pulmonary edema & $20(6.2)$ & $15(7.2)$ & $5(4.4)$ & 0.329 \\
\hline Extracranial trauma & $23(7.1)$ & $13(6.2)$ & $10(8.8)$ & 0.382 \\
\hline Hypovolemic/cardiogenic shock & $18(5.6)$ & $12(5.7)$ & $6(5.3)$ & 0.872 \\
\hline Aspirative syndromes & $13(4)$ & $9(4.3)$ & $4(3.5)$ & 0.739 \\
\hline Pulmonary embolism & $9(2.8)$ & $6(2.9)$ & $3(2.7)$ & 0.911 \\
\hline Others & $59(18.3)$ & $36(17.2)$ & $23(20.4)$ & 0.488 \\
\hline
\end{tabular}

Data presented as median (25 to 75\% interquartile range) or $n$ (\%). COPD, chronic obstructive pulmonary disease; SAPS3, Simplified Acute Physiology Score 3; SOFA, Sequential Organ Failure Assessment. ${ }^{\mathrm{a}} \mathrm{P}$ value of the comparison between light and deep sedation. 
Table 3 Clinical outcomes according to sedation depth

\begin{tabular}{|c|c|c|c|c|}
\hline Clinical outcomes & All patients $(n=322)$ & Light sedation $(n=209)$ & Deep sedation $(n=113)$ & $P$ value $^{\mathrm{a}}$ \\
\hline \multicolumn{5}{|l|}{ Respiratory data } \\
\hline ARDS mild & $50(15.5)$ & $35(16.7)$ & $15(13.3)$ & 0.521 \\
\hline ARDS moderate/severe & $49(15.2)$ & $35(16.7)$ & $14(12.4)$ & \\
\hline $\mathrm{PO}_{2} / \mathrm{FiO}_{2}$ ratio & 278 (208 to 339) & 268 (208 to 329) & 282 (208 to 353) & 0.486 \\
\hline Tracheostomy & $90(28.3)$ & $46(22)$ & $44(38.9)$ & 0.001 \\
\hline Extubation failure & $42(13.8)$ & $32(15.3)$ & $10(8.8)$ & 0.119 \\
\hline Length of ventilatory support (days) & 5 (3 to 9 ) & 5 (3 to 9 ) & $7(4$ to 10$)$ & 0.041 \\
\hline Ventilator-free days & 17.5 (0 to 23.3) & $21(0$ to 25$)$ & $0(0$ to 21$)$ & $<0.001$ \\
\hline \multicolumn{5}{|l|}{ ICU support } \\
\hline Renal replacement therapy & $69(21.7)$ & $54(25.8)$ & $15(13.3)$ & 0.008 \\
\hline Vasopressors & $247(77.4)$ & $162(77.5)$ & $85(75.2)$ & 0.629 \\
\hline \multicolumn{5}{|l|}{ Outcomes } \\
\hline ICU length of stay (days) & $11(6$ to 19$)$ & $11(6$ to 19$)$ & $11(6$ to 18$)$ & 0.633 \\
\hline Hospital length of stay (days) & 20 (12 to 34$)$ & 21 (13 to 35.8$)$ & 19 (10 to 27$)$ & 0.084 \\
\hline ICU mortality & $98(30.4)$ & $56(26.8)$ & $42(37.2)$ & 0.054 \\
\hline Hospital mortality & 125 (38.8) & 73 (34.9) & $52(46)$ & 0.051 \\
\hline
\end{tabular}

Data presented as median ( 25 to $75 \%$ interquartile range) or $n$ (\%). ARDS, acute respiratory distress syndrome; $\mathrm{PO}_{2} / \mathrm{FiO}_{2}$, arterial partial pressure of oxygen/fraction of inspired oxygen; ${ }^{\text {a }} P$ value of the comparison between light and deep sedation.

for dexmedetomidine, $P=0.005)$. These findings may be attributed to a rapid onset and offset of action of these drugs and their easiness to titrate, while benzodiazepines are more likely to accumulate, especially during continuous infusion and when associated with other drugs $[26,27]$. Recent studies demonstrate that sedation with benzodiazepines aiming at the same target is usually associated with a higher rate of sedation depth beyond the target as compared with dexmedetomidine [28].

Although important studies were published recently, a systematic review published in 2010 showed that clinical trials on sedation are commonly reported as low quality,

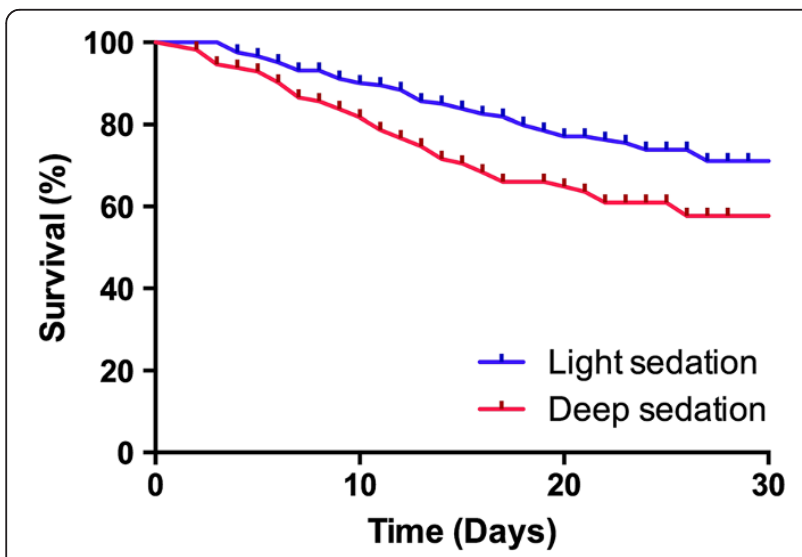

Figure 2 Kaplan-Meier analysis depicting the impact of sedation depth on hospital mortality. Blue line, patients with light sedation at day 2 ; red line, patients with deep sedation at day 2. $P=0.051$. mainly due to their design (for example, before and after studies), heterogeneous protocols and the relatively small number of patients in a single center or few centers [29]. These factors generate limited evidence to guide sedation drug choice and administration strategies in mechanically ventilated patients. Moreover, most studies - including recent randomized clinical trials - have enrolled patients 24 to 48 hours after the initiation of MV, making the clinical relevance of sedation depth in the early period more difficult to understand. A recent multicenter prospective cohort study by Shehabi and colleagues enrolled 251 patients, aiming to characterize the patterns of early sedation practice in 25 Australia and New Zealand (ANZ) ICUs and to assess its relationship with relevant clinical outcomes. After adjusting for potential confounding, early deep sedation was a predictor of time to extubation and mortality [30]. These results were corroborated by a cohort study in 11 Malaysian hospitals including medical/ surgical patients $(n=259)$ who were sedated and ventilated $\geq 24$ hours [31]. Likewise, in our study we could assess sedation strategies in the first 48 hours of MV and its relevant clinical outcomes in a large number of patients $(n=322)$, and demonstrated that early deep sedation was an independent predictor of hospital mortality.

Unlike the other variables that were also found to be independently associated with mortality in our study, such as ARDS severity, comorbidities and disease severity, sedation depth is a potentially modifiable risk factor for mortality. Implementing sedation protocols to achieve light sedation has been proven feasible and reproducible [32,33]. This 
Table 4 Factors associated with hospital mortality in a multivariate analysis

\begin{tabular}{llll}
\hline Parameter & Odds ratio & 95\% confidence interval & P value \\
\hline Age & 1.02 & 1.00 to 1.03 & 0.047 \\
Charlson comorbidity index $>2$ & 2.06 & 1.44 to 2.94 & $<0.001$ \\
SAPS3 & 1.02 & 1.00 to 1.04 & 0.038 \\
Severe ARDS & 1.44 & 1.09 to 1.91 & 0.011 \\
Deep sedation & 2.36 & 1.31 to 4.25 & 0.004 \\
\hline
\end{tabular}

Area under receiver operating curve for predicted mortality ( $95 \%$ confidence interval) $=0.768(0.718$ to 0.813$), P<0.001$. Hosmer-Lemeshow $X^{2}=6.5670, P=0.5840$. ARDS, acute respiratory distress syndrome; SAPS3, Simplified Acute Physiology Score 3.

evidence is important because deep sedation still seems to be current practice in many ICUs worldwide $[5,13]$ and is present in $35 \%$ of the patients enrolled in the present study. Accordingly, Payen and colleagues observed in their survey a large proportion of patients in a deep state of sedation, and in addition no major changes in sedation depth or sedative dosages occurs during the first week of the ICU stay [34].

Finally, our findings provide validation of the concept that early sedation has a major impact on outcomes. Demonstrating this in a middle-income country in South America is an important step to provide generalizability of previous findings because the main previously published results on this issue are from ANZ ICUs. Several ANZ trials are well known for frequently presenting different results compared with similar interventions in other parts of the world, as demonstrated by studies in the last decade in the critical care field $[35,36]$ and even in the sedation area [37]. This discrepancy is attributed to substantial differences due to the high standards in process of care and staffing patterns, and is consequently translated into lower mortality in ANZ ICUs [38,39].

The present study has some limitations that must be considered. First, the sedation level was not assessed using a specific sedation scale. Nonetheless, although originally created to assess the level of consciousness after head injury, it is known that GCS (the chosen scale) $<9$ denotes a comatose state even in nontraumatic settings, such as cerebral depression by pharmacological cause $[40,41]$. Moreover, the GCS shows excellent correlation and discrimination with the RASS $(r=0.91, P<$ 0.001 ), as described by Ely and colleagues from 1,360 paired observations among 275 adult patients in medical and coronary ICUs [25]. This strong correlation between the RASS and the GCS was also shown in other sedation scale validation studies [42,43], which allows its applicability as a surrogate for sedation depth in the present study.

Another limitation is the potential influence of previous neurological status on GCS values. Data regarding GCS on day 1 were collected in patients who were already sedated and under MV. A reported low GCS could therefore be influenced by the baseline neurological status and not only by sedation strategies, because it may also reflect acute neurological conditions associated with the current illness presented by the critically ill, such as encephalopathy. However, this is not an exclusive limitation of the GCS because this may also occur with the more specific sedation assessment scales such as the RASS or Sedation-Agitation Scale (SAS). Moreover, it is possible that certain patients may have required larger sedative doses on day 2 of MV for other reasons (ICU procedures, for instance) and we did not collect these data. In order to minimize the impact of other conditions in GCS values, we excluded patients with primary or known acute neurological disorders and included only patients under sedation in the present study. Considering the potential confounders mentioned above, the strong association between deep sedation and mortality must be analyzed regarding our interpretation of GCS values mainly as a surrogate of sedation depth.

Finally, we have not evaluated the presence of delirium. In mechanically ventilated patients, delirium is an independent predictor of hospital and 6-month mortality $[6,44]$. These outcomes are shown even in light sedated patients, where a dose-effect response was described [45]. Despite this clinical relevance, the incidence of delirium could not be evaluated in our study, since it was not the aim of the primary analysis. Finally, participant ICUs reported the existence of a sedation protocol, but the actual adherence for local recommendations was not assessed in the present study as it was beyond its initial scope.

\section{Conclusions}

Early deep sedation is associated with worse outcomes and constitutes an independent predictor of hospital mortality in a prospective cohort of mechanically ventilated patients. Randomized clinical trials should be designed to address the impact of light versus deep sedation in the early phase (<48 hours) of MV.

\section{Key messages}

- Early deep sedation is associated with longer duration of ventilator support and higher need for tracheostomy in mechanically ventilated patients. 
- Early sedation depth is independently associated with increased hospital mortality.

- Sedation depth is a potentially modifiable risk factor for adverse outcomes; future clinical trials of light sedation with early $(<24$ hours) randomization of patients should therefore be encouraged.

\section{Additional file}

Additional file 1: Is a table listing the sites, investigators and institutional review boards that participated in the Epidemiology of Respiratory Insufficiency in Critical Care study.

\section{Abbreviations}

ANZ: Australia and New Zealand; ARDS: acute respiratory distress syndrome; GCS: Glasgow Coma Scale; MV: mechanical ventilation; RASS: Richmond Agitation-Sedation Scale; SAPS3: Simplified Acute Physiology Score 3; SOFA: Sequential Organ Failure Assessment.

\section{Competing interests}

This study was performed with institutional funds. JIFS received honoraria and unrestricted research grants from Hospira, Inc. São Paulo, Brazil, but this did not interfere with the design, analysis or the elaboration of the manuscript and therefore with adherence to the ethical requirements of the journal. The remaining authors declare that they have no competing interests.

\section{Authors' contributions}

LMST participated in study conception, data acquisition, data analysis and interpretation, and drafting of the manuscript. LCPA participated in study conception, data acquisition, data analysis and interpretation, and drafting of the manuscript. MP participated in study conception, data analysis and revising the manuscript for important intellectual content. GS participated in study conception, data acquisition, data analysis and drafting of the manuscript. APNJr participated in data acquisition, drafting of the manuscript and revising the manuscript for important intellectual content. AR-N participated in data acquisition and revising the manuscript for important intellectual content. LT participated in data acquisition and revising the manuscript for important intellectual content. VCdS-D participated in data acquisition and revising the manuscript for important intellectual content. AT participated in data acquisition and revising the manuscript for important intellectual content $\mathrm{TL}$ participated in data acquisition and revising the manuscript for important intellectual content. CP participated in data acquisition and revising the manuscript for important intellectual content. FBC participated in data acquisition and revising the manuscript for important intellectual content. MdOM participated in data acquisition and revising the manuscript for important intellectual content. FPG participated in data acquisition and revising the manuscript for important intellectual content. FRM participated in data acquisition and revising the manuscript for important intellectual content. FD-P participated in data acquisition and revising the manuscript for important intellectual content. AGRdC participated in data acquisition and revising the manuscript for important intellectual content. RBdS participated in data acquisition and revising the manuscript for important intellectual content. PFGMMT participated in data acquisition and revising the manuscript for important intellectual content. MS participated in study conception, data analysis and interpretation, and drafting of the manuscript. JIFS participated in study conception, data analysis and interpretation, and drafting of the manuscript. All authors approved the final copy of the manuscript.

\section{Acknowledgements}

This study was funded by the Research and Education Institute from Hospital Sírio-Libanês, São Paulo and the D'Or Institute for Research and Education, Rio de Janeiro, Brazil. The funding institutions had no active role in the design, analysis and interpretation of the results or in the publication process. The study was supported by the Brazilian Research in Intensive Care Network.

\section{Author details}

${ }^{1}$ Hospital Copa D’Or, Rua Figueiredo de Magalhães 875, Rio de Janeiro 22031-010, Brazil. ²Research and Education Institute, Hospital Sírio-Libanês, Rua Cel. Nicolau dos Santos 69, São Paulo 01308-060, Brazil. ${ }^{3}$ ICU, Emergency Medicine Department, Hospital das Clinicas da Faculdade de Medicina da Universidade de São Paulo, Av. Eneas Carvalho Aguiar 255, São Paulo 05403-000, Brazil. ${ }^{4}$ ICU, Hospital São Camilo Pompeia, Av. Pompeia 1178, São Paulo 05022-000, Brazil. ${ }^{5}$ CEPETI - Centro de Estudos e Pesquisas em Terapia Intensiva, Rua Monte Castelo 366, Curitiba 82530-200, Brazil. ${ }^{6}$ ICU, Instituto Nacional de Câncer - Hospital do Câncer I, Praça Cruz Vermelha 23, Rio de Janeiro 20230-130, Brazil. ${ }^{7}$ ICU, Hospital Pasteur, Av. Amaro Cavalcanti 495, Rio de Janeiro 20735-040, Brazil. ${ }^{8}$ Rede Institucional de Pesquisa e Inovação em Medicina Intensiva (RIPIMI), Irmandade da Santa Casa de Misericórdia de Porto Alegre, Rua Professor Annes Dias 285 - Centro Histórico, Porto Alegre 90020-090, Brazil. ' ICU, Vitoria Apart Hospital, Rodovia BR-101 Norte, Km 2, 38 Boa Vista II, Serra, ES 29161-900, Brazil. ${ }^{10} \mathrm{ICU}$, Hospital Mater Dei, Rua Gonçalves Dias 2700 (Bloco I), Belo Horizonte 30140-093, Brazil. ${ }^{11}$ ICU, Hospital Santa Luzia, SHLS 716 - Conjunto E, Brasília 70390-902, Brazil. ${ }^{12}$ ICU, Hospital São Luiz, Unidade Itaim, Rua Doutor Alceu de Campos Rodrigues 95, São Paulo 04544-000, Brazil. ${ }^{13}$ ICU, Anesthesiology, Pain and Intensive Care Department, Universidade Federal de São Paulo, Rua Napoleão de Barros, $7156^{\circ}$ andar, São Paulo 04024-900, Brazil. ${ }^{14}$ ICU, Hospital São José Criciúma, Rua Coronel Pedro Benedet 630, Criciúma 88801-250, Brazil. ${ }^{15}$ ICU, UDI Hospital, Av Professor Carlos Cunha 2000, São Luis 65076-820, Brazil. ${ }^{16}$ ICU, Hospital Universitário da Universidade de São Paulo, Av Prof. Lineu Prestes 2565 Cidade Universitária, São Paulo 05508-000, Brazil. ${ }^{17}$ ICU, Surgical Emergency Department, Hospital das Clinicas da Faculdade de Medicina da Universidade de São Paulo, Av. Eneas Carvalho Aguiar 255, São Paulo 05403-000, Brazil. ${ }^{18}$ IDOR D’Or Institute for Research and Education, Rua Diniz Cordeiro 30, Rio de Janeiro 22281-100, Brazil. ${ }^{19}$ Postgraduate Program, Instituto Nacional de Câncer, $10^{\circ}$ Andar, Praça Cruz Vermelha 23, Rio de Janeiro 20230-130, Brazil.

Received: 1 March 2014 Accepted: 23 June 2014

Published: 21 July 2014

\section{References}

1. Puntillo KA, Max A, Timsit JF, Vignoud L, Chanques G, Robleda G, RocheCampo F, Mancebo J, Divatia JV, Soares M, lonescu DC, Grintescu IM, Vasiliu IL, Maggiore SM, Rusinova K, Owczuk R, Egerod I, Papathanassoglou ED, Kyranou M, Joynt GM, Burghi G, Freebairn RC, Ho KM, Kaarlola A, Gerritsen RT, Kesecioglu J, Sulaj MM, Norrenberg M, Benoit DD, Seha MS, et al: Determinants of procedural pain intensity in the intensive care unit: the Europain Study. Am J Respir Crit Care Med 2014, 189:39-47.

2. Barr J, Fraser GL, Puntillo K, Ely EW, Gélinas C, Dasta JF, Davidson JE, Devlin JW Kress JP, Joffe AM, Coursin DB, Herr DL, Tung A, Robinson BR, Fontaine DK, Ramsay MA, Riker RR, Sessler CN, Pun B, Skrobik Y, Jaeschke R: Clinical practice guidelines for the management of pain, agitation, and delirium in adult patients in the intensive care unit. Crit Care Med 2013, 41:263-306.

3. Arroliga AC, Thompson BT, Ancukiewicz M, Gonzales JP, Guntupalli KK, Park PK, Wiedemann HP, Anzueto A, Acute Respiratory Distress Syndrome Network: Use of sedatives, opioids, and neuromuscular blocking agents in patients with acute lung injury and acute respiratory distress syndrome. Crit Care Med 2008, 36:1083-1088.

4. Arabi Y, Haddad S, Hawes R, Moore T, Pillay M, Naidu B, Issa A, Yeni B, Grant C, Alshimemeri $A$ : Changing sedation practices in the intensive care unit protocol implementation, multifaceted multidisciplinary approach and teamwork. Middle East J Anesthesiol 2007, 19:429-447.

5. Patel RP, Gambrell M, Speroff T, Scott TA, Pun BT, Okahashi J, Strength C, Pandharipande P, Girard TD, Burgess H, Dittus RS, Bernard GR, Ely EW: Delirium and sedation in the intensive care unit: survey of behaviors and attitudes of 1384 healthcare professionals. Critical Care Med 2009, 37:825-832.

6. Salluh JI, Soares M, Teles JM, Ceraso D, Raimondi N, Nava VS, Blasquez P, Ugarte S, Ibanez-Guzman C, Centeno JV, Laca M, Grecco G, Jimenez E, Árias-Rivera S, Duenas C, Rocha MG, DECCA (Delirium Epidemiology in Critical Care) Study Group: Delirium epidemiology in critical care (DECCA): an international study. Crit Care 2010, 14:R210.

7. Granja C, Gomes E, Amaro A, Ribeiro O, Jones C, Carneiro A, Costa-Pereira A, JMIP Study Group: Understanding posttraumatic stress disorder-related symptoms after critical care: the early illness amnesia hypothesis. Crit Care Med 2008, 36:2801-2809. 
8. Jackson JC, Girard TD, Gordon SM, Thompson JL, Shintani AK, Thomason JW, Pun BT, Canonico AE, Dunn JG, Bernard GR, Dittus RS, Ely EW: Long-term cognitive and psychological outcomes in the awakening and breathing controlled trial. Am J Respir Crit Care Med 2010, 182:183-191.

9. Nelson BJ, Weinert CR, Bury CL, Marinelli WA, Gross CR: Intensive care unit drug use and subsequent quality of life in acute lung injury patients. Crit Care Med 2000, 28:3626-3630.

10. Dasta JF, Kane-Gill SL, Pencina M, Shehabi Y, Bokesch PM, Wisemandle W, Riker RR: A cost-minimization analysis of dexmedetomidine compared with midazolam for long-term sedation in the intensive care unit. Crit Care Med 2010, 38:497-503.

11. Awissi DK, Bégin C, Moisan J, Lachaine J, Skrobik Y: I-SAVE study: impact of sedation, analgesia, and delirium protocols evaluated in the intensive care unit: an economic evaluation. Ann Pharmacother 2012, 46:21-28.

12. Mascia MF, Koch M, Medicis JJ: Pharmacoeconomic impact of rational use guidelines on the provision of analgesia, sedation, and neuromuscular blockade in critical care. Crit Care Med 2000, 28:2300-2306.

13. Salluh JI, Dal-Pizzol F, Mello PV, Friedman G, Silva E, Teles JM, Lobo SM, Bozza FA, Soares M, Brazilian Research in Intensive Care Network: Delirium recognition and sedation practices in critically ill patients: a survey on the attitudes of 1015 Brazilian critical care physicians. J Crit Care 2009, 24:556-562

14. Shinotsuka CR, Salluh Jl: Perceptions and practices regarding delirium, sedation and analgesia in critically ill patients: a narrative review. Rev Bras Ter Intensiva 2013, 25:155-161.

15. Mehta S, Burry L, Cook D, Fergusson D, Steinberg M, Granton J, Herridge M, Ferguson N, Devlin J, Tanios M: Daily sedation interruption in mechanically ventilated critically ill patients cared for with a sedation protocol: a randomized controlled trial. JAMA 2012, 308:1985-1992.

16. Jakob SM, Ruokonen E, Grounds RM, Sarapohja T, Garratt C, Pocock SJ, Bratty JR, Takala J, Dexmedetomidine for Long-Term Sedation Investigators: Dexmedetomidine vs midazolam or propofol for sedation during prolonged mechanical ventilation: two randomized controlled trials. JAMA 2012, 307:1151-1160.

17. Riker RR, Shehabi Y, Bokesch PM, Ceraso D, Wisemandle W, Koura F, Whitten P, Margolis BD, Byrne DW, Ely EW, Rocha MG, SEDCOM (Safety and Efficacy of Dexmedetomidine Compared With Midazolam) Study Group: Dexmedetomidine vs. midazolam for sedation of critically ill patients: a randomized trial. JAMA 2009, 301:489-499.

18. Azevedo LC, Park M, Salluh Jl, Rea-Neto A, Souza-Dantas VC, Varaschin P, Oliveira MC, Tierno PF, Dal-Pizzol F, Silva UV, Knibel M, Nassar AP Jr, Alves RA, Ferreira JC, Teixeira C, Rezende V, Martinez A, Luciano PM, Schettino G, Soares M, ERICC (Epidemiology of Respiratory Insufficiency in Critical Care) investigators: Clinical outcomes of patients requiring ventilator support in Brazilian intensive care units: a multicenter, prospective, cohort study. Crit Care 2013, 17:R63.

19. Charlson ME, Pompei $P$, Alex KL, MacKenzie CR: A new method of classifying prognostic comorbidity in longitudinal studies: development and validation. J Chronic Dis 1987, 40:373-383.

20. Moreno RP, Metnitz PG, Almeida E, Jordan B, Bauer P, Campos RA, lapichino G, Edbrooke D, Capuzzo M, Le Gall JR, SAPS 3 Investigators: SAPS 3 - from evaluation of the patient to evaluation of the intensive care unit. Intensive Care Med 2005, 31:1345-1355.

21. Vincent JL, Moreno R, Takala J, Willatts S, De Mendonça A, Bruining H, Reinhart CK, Suter PM, Thijs LG: The SOFA (Sepsis-Related Organ Failure Assessment) score to describe organ dysfunction/failure. On behalf of the Working Group on Sepsis-Related Problems of the European Society on Intensive Care Medicine. Intensive Care Med 1996, 22:707-710

22. Levy MM, Fink MP, Marshall JC, Abraham E, Angus D, Cook D, Cohen J, Opal SM, Vincent JL, Ramsay G, SCCM/ESICM/ACCP/ATS/SIS: International Sepsis Definitions Conference. Crit Care Med 2003, 31:1250-1256.

23. Rosolem MM, Rabello LS, Lisboa T, Caruso P, Costa RT, Leal JV, Salluh J Soares M: Critically ill patients with cancer and sepsis: clinical course and prognostic factors. J Crit Care 2012, 27:301-307.

24. Definition Task Force ARDS, Ranieri VM, Rubenfeld GD, Thompson BT, Ferguson ND, Caldwell E, Fan E, Camporota L, Slutsky AS: Acute respiratory distress syndrome: the Berlin Definition. JAMA 2012, 307:2526-2533.

25. Ely EW, Truman B, Shintani A, Thomason JW, Wheeler AP, Gordon S, Francis J, Speroff T, Gautam S, Margolin R, Sessler CN, Dittus RS, Bernard GR: Monitoring sedation status over time in ICU patients. Reliability and validity of the Richmond Agitation-Sedation Scale (RASS). JAMA 2003, 289:2983-2991.

26. Devlin JW, Roberts R: Pharmacology of commonly used analgesics and sedatives in the ICU: benzodiazepines, propofol, and opioids. Crit Care Clin 2009, 25:431-449. vii.

27. Hughes CG, McGrane S, Pandharipande PP: Sedation in the intensive care setting. Clin Pharmacol 2012, 4:53-63.

28. Pandharipande PP, Pun BT, Herr DL, Maze M, Girard TD, Miller RR, Shintani AK, Thompson JL, Jackson JC, Deppen SA, Stiles RA, Dittus RS, Bernard GR, Ely EW: Effect of sedation with dexmedetomidine vs lorazepam on acute brain dysfunction in mechanically ventilated patients: the MENDS randomized controlled trial. JAMA 2007, 298:2644-2653.

29. Jackson DL, Proudfoot CW, Cann KF, Walsh T: A systematic review of the impact of sedation practice in the ICU on resource use, costs and patient safety. Crit Care 2010, 14:R59.

30. Shehabi Y, Bellomo R, Reade MC, Bailey M, Bass F, Howe B, McArthur C, Seppelt IM, Webb S, Weisbrodt L, Sedation Practice in Intensive Care Evaluation (SPICE) Study Investigators; ANZICS Clinical Trials Group: Early intensive care sedation predicts long-term mortality in ventilated critically ill patients. Am J Respir Crit Care Med 2012, 186:724-731.

31. Shehabi Y, Chan L, Kadiman S, Alias A, Ismail WN, Tan MA, Khoo TM, Ali SB, Saman MA, Shaltut A, Tan CC, Yong CY, Bailey M, Sedation Practice in Intensive Care Evaluation (SPICE) Study Group Investigators: Sedation depth and long-term mortality in mechanically ventilated critically ill adults: a prospective longitudinal multicentre cohort study. Intensive Care Med 2013, 39:910-918.

32. Pun BT, Balas MC, Davidson J: Implementing the, PAD guidelines: top ten points to consider. Semin Respir Crit Care Med 2013, 2013:223-235.

33. Mansouri P, Javadpour S, Zand F, Ghodsbin F, Sabetian G, Masjedi M, Tabatabaee HR: Implementation of a protocol for integrated management of pain, agitation, and delirium can improve clinical outcomes in the intensive care unit: a randomized clinical trial. J Crit Care 2013, 28:918-922.

34. Payen JF, Chanques G, Mantz J, Hercule C, Auriant I, Leguillou JL, Binhas M, Genty C, Rolland C, Bosson JL: Current practices in sedation and analgesia for mechanically ventilated critically ill patients: a prospective multicenter patient-based study. Anesthesiology 2007, 106:687-695. quiz 891-892

35. NICE-SUGAR Study Investigators, Finfer S, Chittock DR, Su SY, Blair D, Foster D, Dhingra V, Bellomo R, Cook D, Dodek P, Henderson WR, Hébert PC, Heritier S, Heyland DK, McArthur C, McDonald E, Mitchell I, Myburgh JA, Norton R, Potter J, Robinson BG, Ronco JJ: Intensive versus conventional glucose control in critically ill patients. N Engl J Med 2009, 360:1283-1297.

36. Ho BCH, Bellomo R, McGain F, Jones D, Naka T, Wan L, Braitberg G: The incidence and outcome of septic shock patients in the absence of early goal directed therapy. Crit Care 2006, 10:R80.

37. Bucknall TK, Manias E, Presneill JJ: A randomized trial of protocol-directed sedation management for mechanical ventilation in an Australian intensive care unit. Crit Care Med 2008, 36:1444-1450.

38. Judson JA, Fisher MM: Intensive care in Australia and New Zealand. Crit Care Clin 2006, 22:407-423. vii-viii.

39. Bellomo R, Stow PJ, Hart GK: Why is there such a difference in outcome between Australian intensive care units and others? Curr Opin Anaesthesiol 2007, 20:100-105.

40. Moulton C, Pennycook A, Makower R: Relation between Glasgow coma scale and the gag reflex. BMJ 1991, 303:1240-1241.

41. Teasdale G, Knill-Jones $R$, van der Sande J: Observer variability in assessing impaired consciousness and coma. J Neurol Neurosurg Psychiatry 1978, 41:603-610.

42. Sessler CN, Gosnell MS, Grap MJ, Brophy GM, O'Neal PV, Keane KA, Tesoro EP, Elswick RK: The Richmond Agitation-Sedation Scale. Validity and reliability in adult intensive care unit patients. Am J Respir Care Med 2012, 166:1338-1344.

43. Benítez-Rosario MA, Castillo-Padrós M, Garrido-Bernet B, González-Guillermo T, Martínez-Castillo LP, González A, Members of the Asocación Canaria de Cuidados Paliativos (CANPAL) Research Network: Appropriateness and reliability testing of the modified Richmond agitation-sedation scale in Spanish patients with advanced cancer. J Pain Symptom Manage 2013, 45:1112-1119. 
44. Ely EW, Shintani A, Truman B, Speroff T, Gordon SM, Harrell FE Jr, Inouye SK, Bernard GR, Dittus RS: Delirium as a predictor of mortality in mechanically ventilated patients in the intensive care unit. JAMA 2004, 291:1753-1762.

45. Shehabi Y, Riker RR, Bokesch PM, Wisemandle W, Shintani A, Ely EW, SEDCOM (Safety and Efficacy of Dexmedetomidine Compared With Midazolam) Study Group: Delirium duration and mortality in lightly sedated, mechanically ventilated intensive care patients. Crit Care Med 2010, 38:2311-2318.

doi:10.1186/cc13995

Cite this article as: Tanaka et al:: Early sedation and clinical outcomes of mechanically ventilated patients: a prospective multicenter cohort study. Critical Care 2014 18:R156.

\section{Submit your next manuscript to BioMed Central and take full advantage of:}

- Convenient online submission

- Thorough peer review

- No space constraints or color figure charges

- Immediate publication on acceptance

- Inclusion in PubMed, CAS, Scopus and Google Scholar

- Research which is freely available for redistribution 